\title{
Revascularización del tronco coronario distal apoyada en sistema de litoplastia coronaria: experiencia inicial en España
}

First left main coronary revascularization with adyuvant intracoronary lithotripsy in Spain

Raymundo Ocaranza-Sánchez*, Rosa A. Abellás-Sequeiros y Carlos González-Juanatey

Unidad de Cardiología Intervencionista. Hospital Universitario Lucus Augusti, Lugo, España

\section{Caso clínico}

Se trata de un paciente varón de 83 años de edad, exfumador y dislipémico, con antecedente de cardiopatía isquémica sometida a revascularización percutánea (RP) sobre descendente anterior (DA) media y circunfleja (Cx) proximal en 2001. Ingresa en la unidad de cuidados intensivos del centro de los autores con el diagnóstico de síndrome coronario agudo sin elevación del segmento ST (SCASEST) tipo infarto agudo de miocardio sin elevación del ST (IAMSEST). El electrocardiograma de ingreso no presenta alteraciones agudas de la repolarización y en el ecocardiograma se documenta una función sistólica biventricular conservada sin alteraciones de la contractilidad segmentaria ni valvulopatías significativas. La coronariografía diagnóstica muestra una lesión grave de $85 \%$ con abundante calcio en el tronco coronario izquierdo $(\mathrm{TCl})$ que afecta a los ostia de DA y CX, con Medina de 1-1-1 (Esquema 1) y (Fig. 1A y B). Stents implantados sobre DA y $\mathrm{Cx}$, sin reestenosis.

Tras una sesión médico-quirúrgica, se decide RP sobre la lesión de TCl distal. El gran componente cálcico de la placa estenosante obligó a planificar la intervención a partir de una exhaustiva modificación de la placa inicial. Se consideró que la aterectomía rotacional no constituía una técnica de primera línea en este caso debido a la discrepancia entre el diámetro de referencia del vaso y los diámetros disponibles de olivas de rotablación. En este contexto se optó por una modificación de placa con el sistema de litoplastia coronaria Shockwave ${ }^{\circledR}$.

En un primer momento, la angulación y la estenosis grave de la lesión a tratar permitieron sólo el paso de guía hacia la DA distal. Sobre ésta se avanzó el sistema de litoplastia Shockwave ${ }^{\circledR}$ y se consiguió el cruce de la lesión de TCI distal hacia la DA ostial. Manteniendo el dispositivo hinchado a 4 atm, se realizó una primera aplicación de 10 pulsos de ondas (con expansión incompleta de la lesión, Fig. 1C, flecha) seguidos de cuatro aplicaciones más de 10 pulsos, cada una con balón de litoplastia a 6 atm. Como resultado, se consiguió una adecuada expansión del balón (Fig. 1D) con apertura parcial de la lesión. Esto permitió el paso de la guía hacia la $\mathrm{Cx}$ distal y la predilatacion del ostium de $\mathrm{Cx}$ con balones scoring de diámetros crecientes (Fig. 1E y F). A continuación se avanzó el balón de litoplastia hacia la Cx ostial (Fig. 1G) y se aplicaron, a una presión nominal de $4 \mathrm{~atm}, 20$ pulsos con aumento de la permeabilidad del vaso a dicho nivel (Fig. 1H).

En virtud del grado de enfermedad y la angulación grave en la salida de ambos ostia coronarios (DA y CX) se optó por una revascularización de TCl de doble stent ( $T$-stent). Así se implantó un primer stent farmacoactivo de $3.5 \mathrm{~mm}$ sobre la $\mathrm{Cx}$ proximal ajustado al ostium y se liberó un segundo stent de everolimus de $3.5 \mathrm{~mm}$ sobre TCI-DA. Se optimizó el resultado final mediante

\section{Correspondencia:}

*Raymundo Ocaranza-Sánchez

E-mail: raymundoocaranza@yahoo.com
Disponible en internet: 09-12-2019 Arch Cardiol Mex. 2019;89(4):403-405 www.archivoscardiologia.com

1405-9940/C 2019 Instituto Nacional de Cardiología Ignacio Chávez. Publicado por Permanyer. Este es un artículo open access bajo la licencia CC BY-NC-ND (http://creativecommons.org/licenses/by-nc-nd/4.0/). 


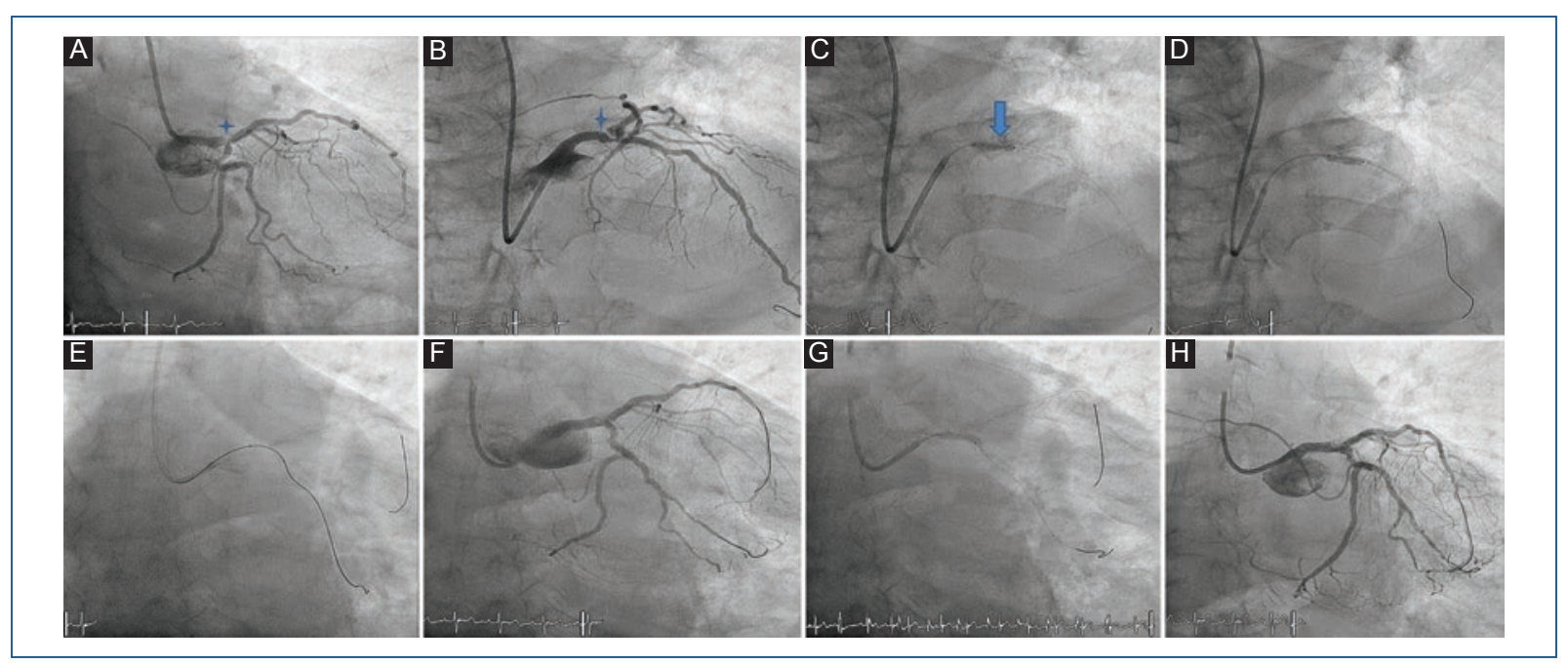

Figura 1. Revascularización coronaria percutánea del tronco coronario izquierdo con litoplastia coronaria. A y B: Angiografía basal. C-G: Balón de litoplastia e implante de stents. H: Resultado final.

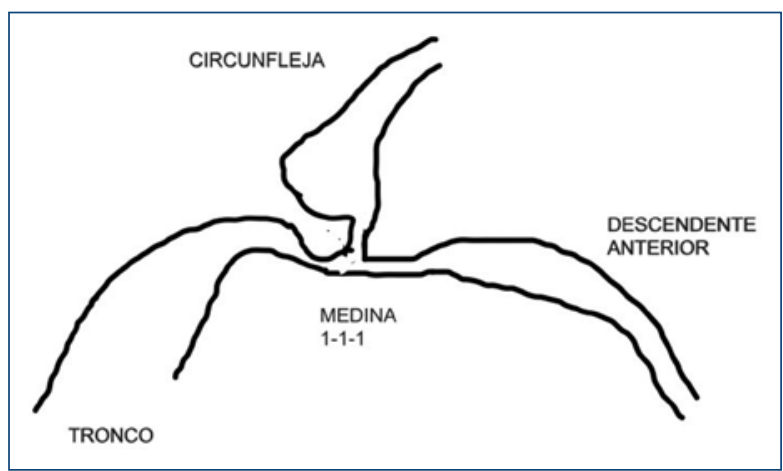

Esquema 1. Representación gráfica de la lesión de tronco distal que afecta los ostia de DA y CX.

técnica de POT con posdilatación con balones no distensibles sobre $\mathrm{TCl}$ (Fig. 2A y B) y se comprobaron adecuadas expansión y aposición del stent en TCl mediante IVUS (Fig. $2 \mathrm{C}$ y D). El paciente recibió el alta bajo doble antiagregación con AAS y clopidogrel, sin mostrar incidencias.

\section{Discusión}

Se presenta la experiencia inicial en España de revascularización percutánea de $\mathrm{TCl}$ apoyado en sistema de modificación de placa Shockwave ${ }^{\circledR}$. Dicha tecnología se basa en el uso de ondas sónicas que, emitidas en pulsos de baja frecuencia, permiten la desestructuracion del calcio en las capas íntima y media de la pared arterial, sin afectar a los tejidos blandos, al fracturar la

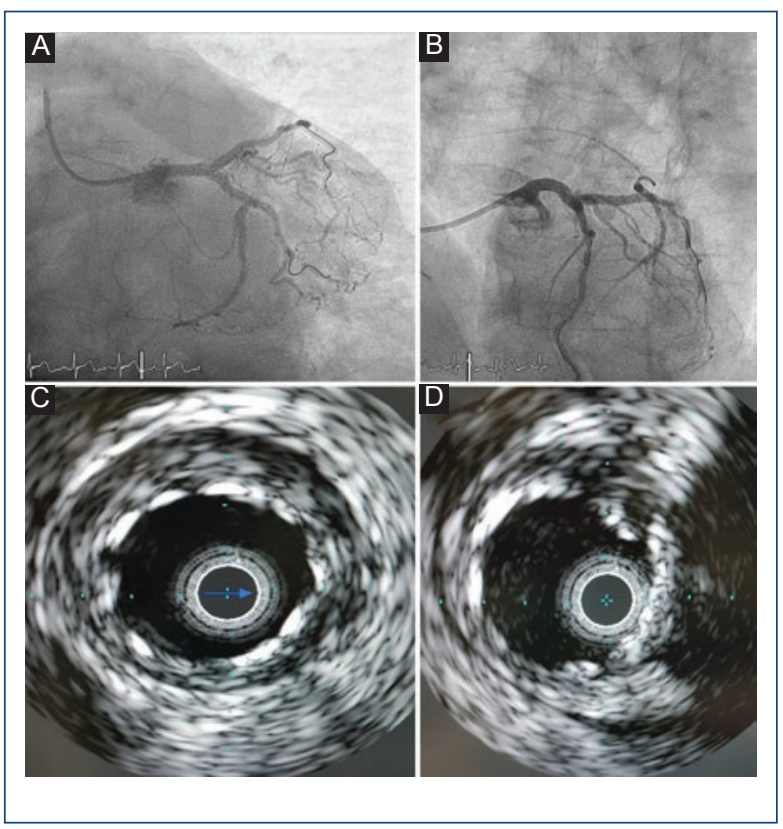

Figura 2. Resultado final angiográfico y por IVUS tras revascularización de TCl. A y B: Resultado angiográfico final. C-D: Imágenes de IVUS mostrando adecuada expansión y aposición del stent.

placa y tornarla dilatable. El dispositivo consta de un balón de angioplastia de rápido intercambio de diámetros de 2.5 a $4 \mathrm{~mm}$ y una longitud fija de $12 \mathrm{~mm}$, que contiene en su interior dos sensores que liberan la señal acústica. Dichas ondas, en contacto con el medio salino de relleno del balón, generan una onda de expansión que se perpetúa sobre el calcio y da lugar a su 
modificación, tras lo cual se puede realizar el implante del stent sin riesgo de infraexpansión de éste. El perfil de cruce del balón permite su uso a través de catéteres guía $6 \mathrm{~F}$ por lo que, tal y como ocurrió en este caso, el acceso radial puede ser el de elección con este dispositivo. Por otro lado, la sencillez de su uso es un punto importante comparado con otros dispositivos de modificación de placa, como la aterectomía en sus diferentes versiones. De acuerdo con el estudio primario del dispositivo DISRUPT CAD II', dicho procedimiento no produce complicaciones agudas, como perforación, oclusión aguda o fenómenos de nulo flujo (no-flow) o bajo flujo (slowflow) $^{1,2}$. Además, se observa un mayor rendimiento con mayor fractura y modificación de placa en los casos en los que la carga de calcio es mayor y circunferencial, lo cual reduce el índice de excentricidad posterior al implante del stent, con mejor simetría del vaso final ${ }^{2,3}$.

Con este caso se sustenta la eficacia y seguridad de esta nueva técnica de modificación de placa de alto contenido cálcico en un escenario de gran complejidad, como es la bifurcación de TCl.

\section{Financiación}

No existe financiación para esta publicación.

\section{Conflicto de intereses}

No hay conflicto de intereses.

\section{Responsabilidades éticas}

Protección de personas y animales. Los autores declaran que para esta investigación no se han realizado experimentos en seres humanos ni en animales.

Confidencialidad de los datos. Los autores declaran que en este artículo no aparecen datos de pacientes.

Derecho a la privacidad y consentimiento informado. Los autores declaran que en este artículo no aparecen datos de pacientes.

\section{Bibliografía}

1. Brinton T, Hill J, Ali Z. DISRUPT CAD: a multicenter, prospective, single-arm study of percutaneous lithoplasty prior to stent implantation in heavily calcified coronary lesion. J Am Coll Cardiol. 2016;68 TCT Suppl. Available at: https://www.tctmd.com/slide/disrupt-cad-multicenterprospective-single-arm-study-percutaneouslithoplasty-prior-stent. Accessed July 13, 2017.

2. Ali ZA, Brinton T, Hill JM, Maehara A, Matsumura M, Karimi Galougahi K, et al. Optical coherence tomography characterization of coronary lithoplasty for treatment of calcified lesions: first description. JACC Cardiovasc Imaging. 2017;10 (8):897-906.

3. Serruys PW, Katagiri Y, Onuma Y. Shaking and breaking calcified plaque: lithoplasty, a breakthrough in interventional armamentarium? JACC Cardiovasc Imaging. 2017;10(8):907-11. 